\title{
Comparative Evaluation of Dimensional Accuracy of Impression Techniques for Parallel Implants and Implants Placed with Angulation: An in vitro Study
}

\author{
${ }^{1}$ Aditi Prasad, ${ }^{2}$ Laxman Rao
}

\begin{abstract}
Objective: This study aims to measure and compare the accuracy of various implant impression techniques in specimens with parallel implants placed at $90^{\circ}$ to the horizontal plane and at $75^{\circ}$.

Materials and methods: Polyether medium body (3M ESPE Impregum) was selected as the material of choice. Two metal samples with three lab analogs placed in each were used as the master models. One had implants placed at $90^{\circ}$ to the horizontal plane, and the other at $75^{\circ}$. Ten impressions were made each of stock metal tray, closed custom tray and open custom tray techniques. Photographs were taken and measurements were made using Adobe Photoshop software. Intragroup comparisons were done using the analysis of variance (ANOVA) and one way t-test. Intergroup comparison was done using two way t-test.
\end{abstract}

Results: All the techniques studied showed some distortion and the difference had no statistical significance. However, closed custom tray technique gave better results for the $90^{\circ}$ specimen, and open custom tray technique gave better results for the $75^{\circ}$ specimen.

Conclusion: Within the limitations of this study, it can be concluded that provided operator error is minimized and guidelines are followed, it may be possible to achieve impressions of similar accuracy regardless of technique used. However, it was impossible to achieve a level of exactness that would ensure a completely passive fitting prosthesis.

Keywords: Dimensional accuracy, Implant, Implant angulation, Impression accuracy, Impression technique, Parallel implants.

How to cite this article: Prasad A, Rao L. Comparative EvaIuation of Dimensional Accuracy of Impression Techniques for Parallel Implants and Implants Placed with Angulation: An in vitro Study. Int J Oral Implantol Clin Res 2014;5(3):92-98.

\section{Source of support: Nil}

Conflict of interest: None

\section{INTRODUCTION}

The major objective of a multiple implant-supported restoration is to ensure that it exhibits a passive fit on

\footnotetext{
${ }^{1}$ Resident, ${ }^{2}$ Professor and Head

1,2Department of Prosthodontics, Army College of Dental Sciences, Secunderabad, Telangana, India

Corresponding Author: Aditi Prasad, Resident, Department of Prosthodontics, Army College of Dental Sciences, Secunderabad Telangana, India, Phone: 09849346045, e-mail: aprasad312@ gmail.com
}

the implants. ${ }^{1}$ Precise reproduction of implant position and angulations is chiefly dependent on accuracy of the implant impression, which is more critical than for tooth supported restorations since implants lack the compensating physiologic mobility of natural teeth. Failure to meet this objective may result in a progressive loss of fixture integration leading to treatment failure.

Forcibly tightening the superstructure might cause microfracture of bone, a zone of marginal ischemia, and healing with a nonmineralized attachment to the implant. ${ }^{2,3}$ Adequate stress distribution through passively fitting prosthesis also encourages the maintenance of marginal bone close to the implant, ${ }^{4}$ promoting longevity of the prosthesis. ${ }^{5,6}$ Impression techniques are mainly divided into direct (open-tray) technique and indirect (closed-tray) technique. ${ }^{7}$ However, clinically stock metal tray impressions are also utilized, and have been included in this study. Many modifications have also been suggested in previous literature to increase exact relation of the transfer copings to each other. ${ }^{8,9}$

The aims of this study were to apply different types of impression techniques to reference models with implants placed parallel to each other and with a specific angulation.

\section{MATERIALS AND METHODS}

Triangular metal specimens with three lab analogs (ADIN) at its apices were used as the reference models..$^{10}$ One had analogs placed at $90^{\circ}$ angulations to the horizontal plane, and the other at $75^{\circ}$ angulations. They were held in place using a low fusing soldering alloy (Figs 1A to D). Three types of impression trays were used; they were (i) metal stock trays, (ii) closed custom trays and (iii) open custom trays (Figs 2A to D). Metal stock trays (Jabbar) were selected such that at least a minimum of $5 \mathrm{~mm}$ space was obtained around the impression post. Custom impression trays were fabricated using autopolymerizing acrylic resin with $5 \mathrm{~mm}$ space for impression material. Twenty identical custom trays were made by duplication. Windows were created in the same trays for making the open tray impressions after the completion of closed-tray impressions.

The following impressions were made:

- Group 1: Analogs placed parallel to each other at a $90^{\circ}$ angulation to the horizontal plane. 

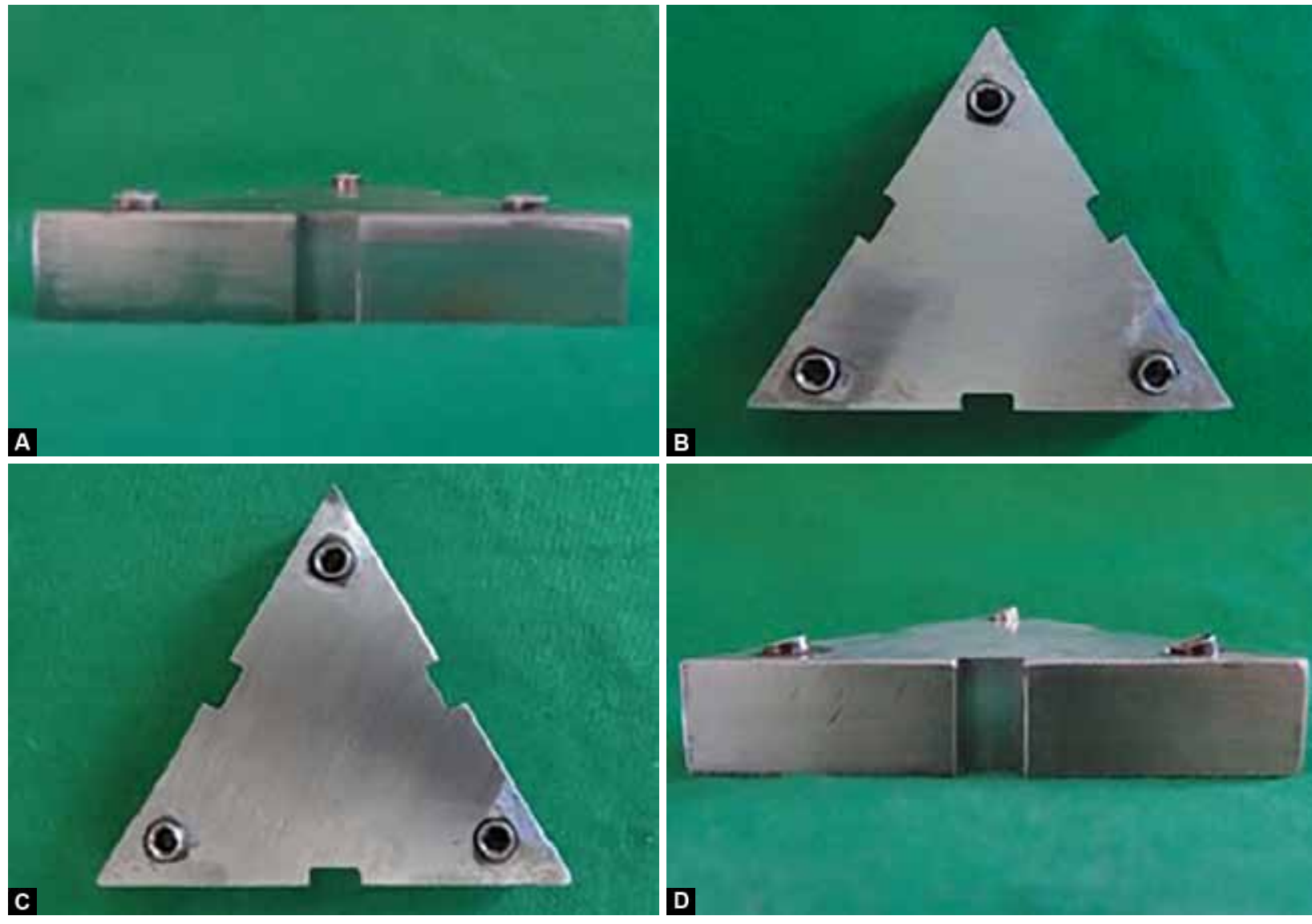

Figs 1A to D: (A and B) Implants placed at $90^{\circ}$ and $(C$ and $D) 75^{\circ}$ to horizontal plane
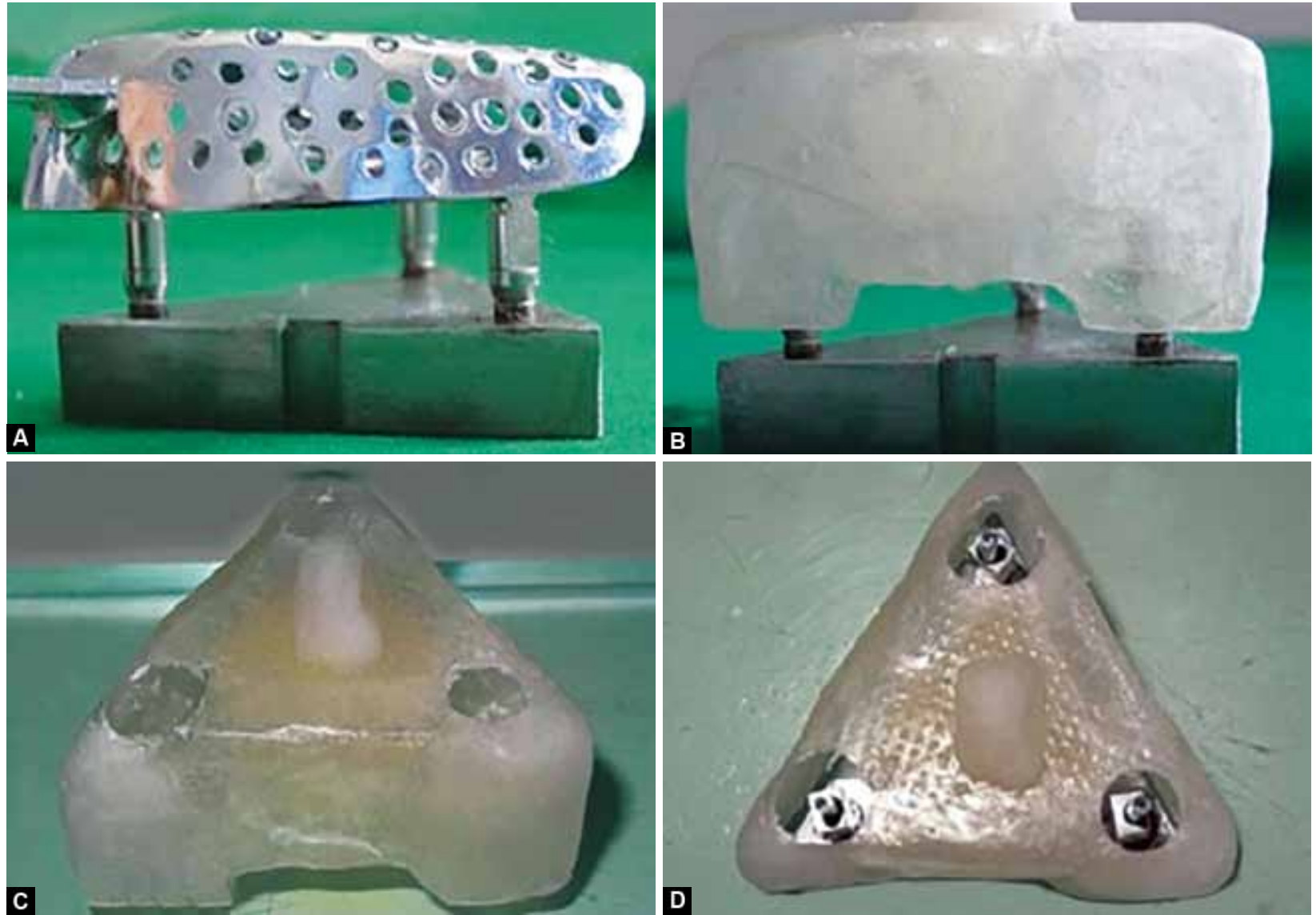

Figs 2A to D: (A) Stock tray, (B) closed custom tray and (C and D) open custom tray 
- Subgroup a: Using stock metal tray

- Subgroup b: Using closed custom tray

- Subgroup c: Using open-window custom tray.

- Group 2: Analogs placed at a $75^{\circ}$ angulation to the horizontal plane.

- Subgroup a: Using stock metal tray

- Subgroup b: Using closed custom tray

- Subgroup c: Using open-window custom tray.

The impression posts were connected to implant analogs with the screws tightened manually such that their flat surfaces were facing outward. Ten impressions were made for each subgroup.

In group 1, the trays were coated with a uniform layer of tray adhesive (3M ESPE polyether adhesive) and were allowed to set for 15 minutes according to manufacturer's instructions. Polyether medium body material (3M ESPE) was mixed for 45 seconds and impressions were allowed to set for 10 minutes as per manufacturer's instructions.

In subgroup a, stock metal trays were used and in subgroup b, closed custom-made trays were used. In subgroup c, open window custom trays were used. Open tray impression copings were splinted together with fast setting plaster just before impression procedure. ${ }^{11}$

The closed tray impressions were separated from the reference model, after which the transfer copings discon- nected from the model were affixed to lab analogs and repositioned in the impressions. In open tray impressions, the transfer copings were unscrewed after the impression material had set; after which the impressions were separated from the model along with the transfer copings. Analogs were then connected to the copings before pouring of the casts. Procedure was repeated for group 2.

All impressions were poured with die stone (Kalrock type IV) using water powder ratio of $23 \mathrm{ml}$ of water to 100 gm of powder according to manufacturer's instructions. These were mixed using vacuum mixer before pouring of cast (Cuumyx Confident). Casts were allowed to set for 1 hour and regular standard straight abutments with $1 \mathrm{~mm}$ collar height were attached to analogs before photographs were taken for measurements.

Putty indices were fabricated for positioning of casts during photographs, one type of measurement was designed to measure relative distortion, i.e., inter-implant distances in group 1 and quantitative angulations in group 2 . The other used an external reference point for measuring absolute distortion, lateral shift of each abutment from a point on an externally placed metal ruler for both groups (Figs 3A to D). Photographs were taken using a Canon DSLR $1100 \mathrm{D}$ at a $55 \mathrm{~mm}$ fixed focal distance using a tripod, and measurements were made using Adobe Photoshop CS 5. All clinical,
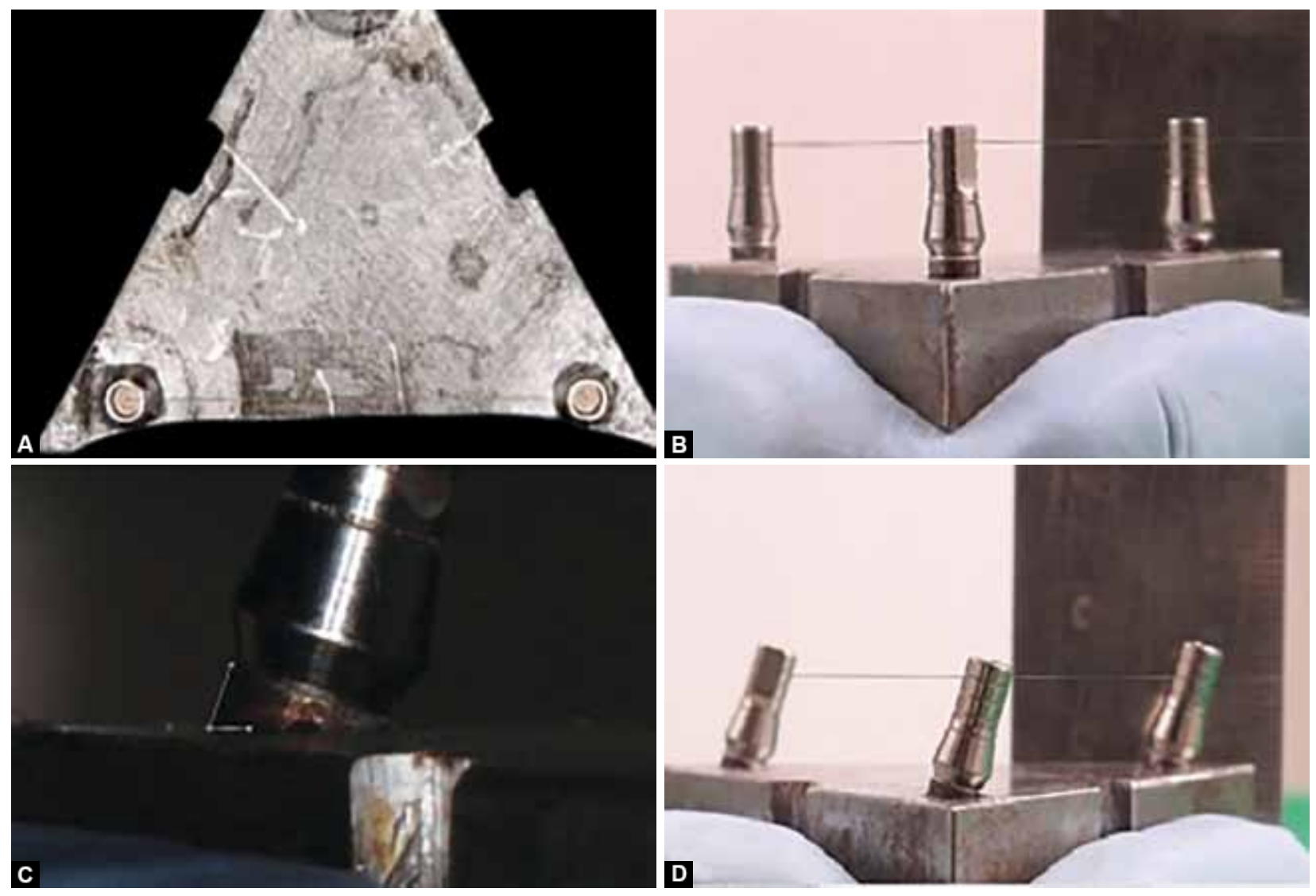

Figs 3A to D: (A) Inter implant distance measured in group 1, (B) lateral shift measured in group 2, (C) angulation measured in group 2, and (D) lateral shift measured in group 2 
laboratory procedures, and measurements were performed by the same operator. Distances were measured in pixels and angulations in degrees with accuracy up to 0.01 .

All values of relative distortion were compared to the true values of the reference values using one way student t-test. Intragroup analysis to compare subgroups used analysis of variance (ANOVA) test. Intergroup analysis using only the lateral shift measurements (common to both groups) utilized the two way t-test to compare percentage errors and compute statistical significance.

\section{RESULTS}

Intergroup analysis of percentage errors in lateral shift measurements made in the vertical plane with external reference point were analyzed using two way sample t-test (Table 3). Although, statistically insignificant ( $p>$ $0.05)$, stock tray measurements showed greater error in measurements of implants in the $75^{\circ}$ samples as compared to those placed at $90^{\circ}$. Closed custom tray measurements showed greater error in the angulated samples than in the $90^{\circ}$ ones, where closed custom trays gave the least error among techniques. Open custom tray measurements showed greater error in the $90^{\circ}$ samples than in the ones with angulations, where they gave the least error among techniques.

Intragroup analysis of group 1 (Table 1) yielded the following results through ANOVA test: data obtained from measurements of inter implant distance for implants placed at $90^{\circ}$ both showed best results with both open and closed custom tray techniques, as compared to stock tray usage which showed a borderline significant error $(\mathrm{p}>0.05)$. The data analyzed through one way t-test also showed insignificant differences from their true values $(p>0.05)$.

Intragroup analysis of group 2 (Table 2) by using ANOVA test confirned that measurements of degree of

Table 1: Intragroup analysis for group 1 using student t-test and ANOVA

\begin{tabular}{|c|c|c|c|c|c|c|c|c|c|c|}
\hline & $\begin{array}{l}\text { Number } \\
\text { of } \\
\text { samples }\end{array}$ & Mean & $\begin{array}{l}\text { Standard } \\
\text { deviation }\end{array}$ & $\begin{array}{l}\text { Standard } \\
\text { error }\end{array}$ & $\begin{array}{l}\text { Mean } \\
\text { difference }\end{array}$ & $\begin{array}{l}\text { Min. 95\% } \\
\text { confidence } \\
\text { interval }\end{array}$ & $\begin{array}{l}\text { Max. 95\% } \\
\text { confidence } \\
\text { interval }\end{array}$ & t-value & $\begin{array}{l}\text { Degree of } \\
\text { freedom }\end{array}$ & $p$-value \\
\hline Stock tray & 30 & 2570.46 & 1.07 & 0.19 & 0.39 & -0.003 & 0.79 & 2.02 & 29 & 0.051 \\
\hline $\begin{array}{l}\text { Closed } \\
\text { custom }\end{array}$ & 30 & 2570.33 & 1.07 & 0.19 & 0.26 & -0.133 & 0.67 & 1.36 & 29 & 0.182 \\
\hline $\begin{array}{l}\text { Open } \\
\text { custom }\end{array}$ & 30 & 2570.40 & 0.96 & 0.17 & 0.33 & -0.028 & 0.69 & 1.88 & 29 & 0.07 \\
\hline \multicolumn{11}{|c|}{ Student t-test: Significance level at $p<0.05$} \\
\hline & \multicolumn{2}{|c|}{ Sum of squares } & \multicolumn{2}{|c|}{ Degree of freedom } & \multicolumn{2}{|c|}{ Mean square } & \multicolumn{2}{|l|}{$f$-value } & \multicolumn{2}{|l|}{$p$-value } \\
\hline Stock tray & \multicolumn{2}{|l|}{0.254} & \multicolumn{2}{|l|}{2} & \multicolumn{2}{|c|}{0.127} & 0.117 & & \multicolumn{2}{|l|}{0.889} \\
\hline $\begin{array}{l}\text { Closed } \\
\text { custom }\end{array}$ & \multicolumn{2}{|l|}{94.040} & \multicolumn{2}{|l|}{87} & \multicolumn{2}{|l|}{1.081} & & & & \\
\hline $\begin{array}{l}\text { Open } \\
\text { custom }\end{array}$ & \multicolumn{2}{|l|}{94.294} & \multicolumn{4}{|l|}{89} & & & & \\
\hline
\end{tabular}

ANOVA test: Significance level at $p<0.05$

Table 2: Intragroup analysis for group 2 using student t-test and ANOVA

\begin{tabular}{|c|c|c|c|c|c|c|c|c|c|c|}
\hline & $\begin{array}{l}\text { Number of } \\
\text { samples }\end{array}$ & Mean & $\begin{array}{l}\text { Standard } \\
\text { deviation }\end{array}$ & $\begin{array}{l}\text { Standard } \\
\text { error }\end{array}$ & $\begin{array}{l}\text { Mean } \\
\text { difference }\end{array}$ & $\begin{array}{l}\text { Min. 95\% } \\
\text { confidence } \\
\text { interval }\end{array}$ & $\begin{array}{l}\text { Max. 95\% } \\
\text { confidence } \\
\text { interval }\end{array}$ & $t$-value & $\begin{array}{l}\text { Degree of } \\
\text { freedom }\end{array}$ & $p$-value \\
\hline Stock tray & 30 & 75.23 & 0.636 & 0.116 & 0.23 & -0.007 & 0.467 & 1.97 & 29 & 0.057 \\
\hline $\begin{array}{l}\text { Closed } \\
\text { custom }\end{array}$ & 30 & 75.22 & 0.984 & 0.18 & 0.225 & -0.141 & 0.593 & 1.25 & 29 & 0.218 \\
\hline $\begin{array}{l}\text { Open } \\
\text { custom }\end{array}$ & 30 & 74.95 & 0.660 & 0.121 & -0.046 & -0.293 & 0.199 & 0.38 & 29 & 0.701 \\
\hline \multicolumn{11}{|c|}{ Student t-test: Significance level at $p<0.05$} \\
\hline & \multicolumn{2}{|c|}{ Sum of squares } & \multicolumn{2}{|c|}{ Degree of freedom } & \multicolumn{2}{|l|}{ Mean square } & \multicolumn{2}{|l|}{$f$-value } & \multicolumn{2}{|l|}{$p$-value } \\
\hline Stock tray & \multicolumn{2}{|l|}{1.509} & \multicolumn{2}{|l|}{2} & \multicolumn{2}{|l|}{0.754} & 1.250 & & \multicolumn{2}{|l|}{0.292} \\
\hline $\begin{array}{l}\text { Closed } \\
\text { custom }\end{array}$ & \multicolumn{2}{|l|}{52.496} & \multicolumn{2}{|l|}{87} & \multicolumn{2}{|l|}{0.603} & & & & \\
\hline $\begin{array}{l}\text { Open } \\
\text { custom }\end{array}$ & \multicolumn{2}{|l|}{54.005} & \multicolumn{4}{|l|}{89} & & & & \\
\hline
\end{tabular}

ANOVA test: Significance level at $p<0.05$ 
Table 3: Intergroup analysis between lateral shift of groups 1 and 2 using two-way t-test and percentage error values

\begin{tabular}{lllllll}
\hline & $\begin{array}{l}\text { Number of } \\
\text { samples }\end{array}$ & $\begin{array}{l}\text { Group 1 } \\
\text { (Percentage error) }\end{array}$ & $\begin{array}{l}\text { Group 2 } \\
\text { (Percentage error) }\end{array}$ & $\begin{array}{l}\text { t-value } \\
\text { Pevalue }\end{array}$ & $\begin{array}{l}\text { Degree of } \\
\text { freedom }\end{array}$ & 0.25 \\
58 & 0.8033 \\
Stock tray & 30 & 0.38113 & 0.89581 & 0.045 & 58 & 0.9646 \\
Closed custom & 30 & 0.14823 & 0.19588 & 0.021 & 58 & 0.9829 \\
Open custom & 30 & 0.15452 & 0.13349 & & &
\end{tabular}

Two-way t-test: Significance level at $p<0.05$

implant angulations showed that the usage of open tray technique gave better results as compared with stock tray and closed custom tray techniques, when used for implants placed at $75^{\circ}(\mathrm{p}>0.05)$. The data analyzed through one way t-test also showed insignificant differences from their true values $(\mathrm{p}>0.05)$.

\section{DISCUSSION}

The influence of impression techniques and implant angulation was proved to be statistically insignificant at the $\mathrm{p}$-value being lesser than 0.05 . This is in agreement with previous studies conducted by Assif et al, ${ }^{12}$ Assif et al, ${ }^{13}$ Vigolo et al,${ }^{14}$ Assuncao et al,${ }^{15}$ Naconecy et al, ${ }^{16}$ Vigolo et al,${ }^{17}$ Cabral and Guedes, ${ }^{18}$ Filho et al, ${ }^{19}$ Wöstmann, ${ }^{20}$ Barrett et al, ${ }^{21}$ Hsu et al, ${ }^{22}$ Herbst et al, ${ }^{23}$ Del'Acqua et al,,${ }^{24}$ Choi et $\mathrm{al},{ }^{25}$ Daoudi et $\mathrm{al}^{26}$ and Conrad et al. ${ }^{27}$

In intergroup analysis, the comparable accuracy of angulated implant impressions may be attributed to the parallelism of the analogs to each other, despite their $75^{\circ}$ angulation to the horizontal plane. Also, the splinting together of the transfer copings in open tray impressions may have yielded better results.

In intragroup analysis of group 1, custom tray impressions were found to be more accurate than stock metal tray impressions. This can be explained by the difference in the thickness of impression material and setting shrinkage of the impression material away from the specimen, because it is adhered to the tray by the adhesive and not to the specimen. This distortion along with differential thickness would result in more distortion. In the same way, the mean error values obtained show that closed custom tray impressions were more accurate then open custom tray impressions.

In group 2, open-tray technique was found to be more accurate than the other techniques. This can be explained by the need to reposition copings with the closed-tray technique and because the abutments are shorter than direct impression copings.

The comparable and high levels of accuracy of impressions, regardless of techniques and angulations used, may have also been influenced by the use of polyether medium body impression material. Impression materials that present with a high shore A hardness number are better suited for implant impression due to increased rigidity which will decrease the amount of copings' movement. Wee et $\mathrm{al}^{28}$ also stated that when using the pick-up implant impression technique, the impression material must fulfill two requirements: rigidity to hold the impression coping and to prevent accidental displacement of the coping when an abutment is connected and minimal positional distortion between abutment replicas as compared with their intraoral implant abutments. They found that the torque required to rotate an impression coping in the impression was found to be maximum in polyether (medium body). Polyether was recommended as the material of choice in several studies due to its high rigidity. ${ }^{12,13,22,29-32}$

As to the intraoperator error variability, the same operator performed all steps and measurements. Small standard deviations were indicative of the dependability and uniformity of the measurement method.

However, errors could be easily introduced during any of the steps required to make an implant master cast. There may have been errors due to the dimensional changes of the impression material, inaccurate repositioning of impression copings, improper connection of components and dimensional changes of the material used to fabricate the master cast. A possible source of error was the fit of the individual impression copings to the implants or implant analogs. This study may not be relevant for more or less than three implants in a clinical situation. Another possible limitation of the current study lies in the measurement protocol. Although, no specific method has been proven to be superior, the measurement of distortion is greatly influenced by the experimental methods and operator reliability. ${ }^{33}$

It is worth stressing that throughout this study, an exact reproduction of the implant position as recorded on the control models was never achieved. Clinically, this could mean that completely passive fit of an implant supported prosthetic superstructure is not attainable yet, despite the impression technique and the laboratory procedures. ${ }^{34}$ Clinical experience and skill of the operator still appear to remain the most important factors to be involved.

This study analyzes both absolute and relative distortion for both the groups and subgroups to verify the results 
obtained from either method. Mostly, similar results were obtained, which could also be attributed to maintaining a uniform space around analogs to minimize volumetric shrinkage of impression material.

Also, this study includes stock metal tray in the techniques of implant impression, since it decreases chairside time significantly and must be tested as an alternative. This study shows that following guidelines and reducing operator error may be able to diminish the effects of other variables in impression accuracy.

\section{MANUFACTURERS' NAME}

- Polyether impression material: Impregum medium body by $3 \mathrm{M}$ ESPE

- Implant analogs and other components: ADIN

- Gypsum products: Kalabhai

- Acrylics: DPI

- Equipment: Confident.

\section{CONCLUSION}

Within the limitations of this study, it can be concluded that:

The influence of technique on impression accuracy was not significant in both the 90 and $75^{\circ}$ angulations.

The open tray technique with splinted impression copings may be recommended for highly unparallel implants.

The closed tray technique gives better results in implants placed parallel to the direction of removal of impression.

\section{REFERENCES}

1. Branemark P1, Zarb GA, Albrektson T. Tissue-integrated prostheses: osseointegration in clinical dentistry. Chicago: Quintessence 1985;11-12:253-257.

2. Skalak R. Biomechanical consideration in osseointegration prosthesis. J Prosthet Dent 1984;49(6):843-848.

3. Urs B, Ioannis K, Rutger P, Bjani P, et al. Technical and biological complications/failures with single crowns and fixed partial dentures on implants: a 10-years prospective cohort study. Clin Oral Imp Res 2005;16(3):326-331.

4. Adell R, Lekholm U, Rockler B, et al. A 15-year study of osseointegrated implants in the treatment of the edentulous jaw. Int $\mathrm{J}$ Oral Surg 1981;10(6):387-416.

5. Quick DC, Holtan JR, Ross GK. Use of a scanning three-dimensional digitizer to evaluate dimensional accuracy of dental impression materials. J Prosthet Dent 1992;68(2):229-235.

6. Nachum S, Michal S, Alon L, et al. A clinical evaluation of fixed partial denture impression. J Prosthet Dent 2005;94(2): $112-117$

7. Haje EE. Direct impression coping for an implant. J Prosthet Dent 1995;74(4):434-493.

8. Burawi G, Hoston F, Byrne D, et al. A comparison of the dimensional accuracy of the splinted and unsplinted impression techniques for the bone-lock implant system. J Prosthet Dent 1997;77(1):68-75.

9. Cary A. Dental implant impression techniques. Clin implant Dent Relat Res 2002;2(3):93-99.

10. Walker MP, Ries D, Borello B. Implant cast accuracy as a function of impression techniques and impression material viscosity. Int J Oral Maxillofac Implants 2008;23(4): 669-674.

11. Assif D, Nissan J, Varsano I, Singer A. Accuracy of implant impression splinted techniques: effect of splinting material. Int J Oral Maxillofac Implants 1999;14(6):885-888.

12. Assif D, Fenton A, Zarb G, et al. Comparative accuracy of implant impression procedures. Int J Period Rest Dent 1992; 12(2):112-121.

13. Assif D, Marshak B, Schmidt A. An accuracy of implant impression techniques. Int J Oral Maxillofac Implants 1996;11(2):216-222.

14. Vigolo P, Majzoub Z, Cordioli G. An evaluation of the accuracy of three techniques used for multiple implant abutment impressions. J Prosthet Dent 2003;89(2):186-192.

15. Assuncao WG, Filho HG, Zaniquelli O. Evaluation of transfer impressions for osseointegrated implants at various angulations. Implant Dent 2004;13(4):358-366.

16. Naconecy MM, Teixeira ER, Shinkai RS, et al. An evaluation of the accuracy of three transfer techniques for implant-supported prostheses with multiple abutments. Int J Oral Maxillofac Implants 2004;19(2):192-198.

17. Vigolo P, Fonzi F, Majzoub Z, et al. An evaluation of impression techniques for multiple internal connection implant prostheses. J Prosthet Dent 2004;92(5):470-476.

18. Cabral LM, Guedes CG. Comparative analysis of four impression techniques for implants. Implant Dent 2007;16(2):187-194.

19. Filho HG, Mazaro JV, Vedovatto E, et al. Accuracy of impression techniques for impants. Part 2-comparison of splinting techniques. J Prosthodont 2009;18(2):172-176.

20. Wöstmann B, Rehmann P, Balkenhol M. Influence of impression technique and material on the accuracy of multiple implant impressions. Int J Prosthodont 2008;21(4): 299-301.

21. Barrett MG, de Rijk WG, Burgess JO. The accuracy of six impression techniques for osseointegrated implants. J Prosthod 1993;2(2):75-82.

22. Hsu CC, Millstein PL, Stein RS. A comparative analysis of the accuracy of implant transfer techniques. J Prosthet Dent 1993; 69(6):588-593.

23. Herbst D, Nel JC, Driessen CH, et al. Evaluation of impression accuracy for osseointegrated implant supported superstructures. J Prosthet Dent 2000;83(5):555-561.

24. Del'Acqua MA, Arioli-Filho JN, Compagnoni MA, et al. Accuracy of impression and pouring techniques for an implant-supported prosthesis. Int J Oral Maxillofac Implants 2008;23(2):226-236.

25. Choi JH, Lim YJ, Yim SH, et al. Evaluation of the accuracy of implant-level impression techniques for internal-connection implant prostheses in parallel and divergent models. Int J Oral Maxillofac Implants 2007;22(5):761-768.

26. Daoudi MF, Setchell DJ, Searson LJ. A laboratory investigation of the accuracy of two impression techniques for single-tooth implants. Int J Prosthodont 2001;14(2):152-158. 
27. Conrad HJ, Pesun IJ, DeLong R, et al. Accuracy of two impression techniques with angulated implants. J Prosthet Dent 2007;97(6):349-356

28. Wee AG. Comparison of impression materials for direct multiimplant impressions. J Prosthet Dent 2000;83(3):323-331.

29. Carr AB. Comparison of impression techniques for a five-implant mandibular model. Int J Oral Maxillofac Implants 1991;6(4): 448-455.

30. Carr AB. Comparison of impression techniques for a two-implant 15 degree divergent model. Int J Oral Maxillofac Implants 1992; 7(4):468-475.
31. Inturregui JA, Aquilino SA, Ryther JS, et al. Evaluation of three impression techniques for osseointegrated oral implants. J Prosthet Dent 1993;69(5):503-509.

32. Phillips K, Goto Y. Alternative implant impression techniques. Compend Contin Educ Dent 2002;23(2):170-172, 174.

33. Nicholls JI. The measurement of distortion: theoretical considerations. J Prosthet Dent 1977;37(5):578-586.

34. Rodney J, Johansen R, Harris W. Dimensional accuracy of two implant impression copings. J Dent Res 1991;70 (special issue):385 (abstr no. 953) 